\title{
Learning about a patient-empowering discourse: Testing the use of a computer simulation with nursing students
}

\author{
Heli Virtanen ${ }^{* 1}$, Helena Leino-Kilpi ${ }^{1,2}$, Sanna Salanterä ${ }^{1,2}$ \\ ${ }^{1}$ Department of Nursing Science, University of Turku, Turku, Finland \\ ${ }^{2}$ Turku University Hospital, Turku, Finland
}

Received: November 16, 2014

Accepted: February 27, 2015

Online Published: March 26, 2015

DOI: $10.5430 /$ jnep.v5n6p 15

URL: http://dx.doi.org/10.5430/jnep.v5n6p15

\begin{abstract}
The development of patient education towards greater patient empowerment requires more competent patient educators. Therefore, there is a need to design novel methods for nursing students to learn about patient education. One such method is the use of computer simulation, which has shown encouraging learning outcomes regarding other nursing interventions. This study was undertaken to evaluate nursing students' knowledge structures of an empowering discourse, and the change in these structures after using a computer simulation program. Furthermore, the aim of the study was to compare these possible changes with the students' background factors. A pretest-posttest design, without a control group, was used. The data were collected from graduating nursing students $(n=43)$ in six Finnish polytechnics using concept maps pre- and post-test in connection to using a computer simulation program. The students' knowledge structures were quite fragmented concerning an empowering discourse both pre- and post-test. About one fifth of the students had an improved knowledge structure post-test. The changes in the students' knowledge structures did not associate with the students' study orientations or with the students' socio-demographic factors. This study provided new insight into students using computer simulation when learning about supporting patient empowerment and recommends further testing of learning methods that facilitate the development of patient educators.
\end{abstract}

Key Words: Patient education, Empowerment, Nursing students, Knowledge structure, Computer simulation

\section{INTRODUCTION}

Patient education is one of the main competence domains in nursing education. ${ }^{[1,2]}$ The importance of learning about educating patients is emphasized in today's healthcare settings with short hospital stays and the growing demand for patient self-care. ${ }^{[3]}$ Nursing students should learn to support patient empowerment, which is seen as crucial for a patient's ability to act and make decisions concerning their health and care. ${ }^{[4]}$ An empowering discourse is one of the methods for supporting patient empowerment. ${ }^{[5,6]}$ In this study, an empowering discourse is defined as a process including a systematic structure $^{[6]}$ (see Figure 1). This systematic structure consists of three phases: initiation, progression and conclusion. ${ }^{[6,7]}$ An empowering discourse contains knowledge of bio-physiological, functional, emotional, social, ethical and financial issues supporting patient empowerment. ${ }^{[4]}$

*Correspondence: Heli Virtanen; Email: heli.virtanen@utu.fi; Address: Department of Nursing Science, University of Turku, Turku, Finland. 
Structure of the empowering discourse

1. Initiation

- Creating of appreciative atmosphere

- Negotiation concerning patient's health problem and

discourse goal

2. Progression

- Focus on issues based on patient's existing knowledge

and knowledge expectations

- Supporting patient's active participation in the discourse

3. Conclusion

- Assessing the achievement of the discourse goal
Content areas of an empowering discourse

1. Bio-fysiological issues e.g. disease, treatment and care

2. Functional issues e.g. moving and daily practices

3. Social issues e.g. social network and support

4. Experiential issues e.g. feelings, emotions and coping

5. Ethical issues e.g. patient rights and participation

6 . Financial issues e.g. costs and financial benefits

Figure 1. Structure of an empowering discourse including content areas

Nursing students should thus gain a coherent knowledge structure for conducting an empowering discourse appropriately. A knowledge structure, also known as cognitive structure ${ }^{[8]}$ or structural knowledge, ${ }^{[9]}$ is defined as a hypothetical construct representing the relationships of concepts in the memory. ${ }^{[10,11]}$ This knowledge structure is always individual, ranging from a well-organized construct with relevant elements to a poorly organized construct with few relevant elements, ${ }^{[8]}$ reflecting different cognitive complexities. ${ }^{[12]} \mathrm{A}$ knowledge structure is primarily based on a student's experiences, education and training, ${ }^{[8]}$ but its development can be supported through pedagogical strategies grounded in constructivist theory. ${ }^{[8,13,14]}$ Constructivism emphasizes learning as an active process through which students construct knowledge individually and independently on the basis of their prior knowledge. ${ }^{[12]}$ Computer simulation is therefore a suitable pedagogical application to support the construction of knowledge structures because it allows students to choose what they aim to learn and how they will progress. ${ }^{[7]}$

Evaluating a knowledge structure is an educationally sound way to assess a student's learning. ${ }^{\left[{ }^{8,15-18]}\right.}$ Students' knowledge structures have been evaluated in many fields of educational research, ${ }^{[15,16,19,20]}$ but very seldom in nursing education. There is evidence that students' knowledge structures for community health nursing can be quite narrow with fewer connected relationships ${ }^{[21]}$ whereas knowledge of science was found to be quite well organized even at the beginning of the students' nursing studies or had become better organized during their studies. ${ }^{[22]}$ However, Leino-Kilpi ${ }^{[23]}$ studied nursing students' knowledge structures of nursing as early as the late 1980s and found them to be poorly organized.

There is no evidence concerning students' knowledge structures of an empowering discourse. However, there is some evidence of nursing students' knowledge of an empowering discourse from the perspective of knowledge development: for example, the development of personal knowledge in an educator's role ${ }^{[24]}$ and knowledge construction based on patients' problems during clinical training. ${ }^{[25]}$ There is also a lack of research concentrating on students' knowledge structures with the use of computer simulation, although simulations have been used in nursing education for teaching critical thinking skills ${ }^{[26]}$ and nursing interventions such as electrocardiogram skills, ${ }^{[27]}$ the human respiratory system, ${ }^{[28]}$ medication administration, ${ }^{[29]}$ critical care management ${ }^{[30,31]}$ and preoperative and postoperative care management. ${ }^{[32]}$ However, these studies have only evaluated students' learning outcomes in terms of their knowledge of interventions. ${ }^{[27,29-32]}$

The issues associated with students' knowledge structures are not well known, although these structures are known to be individual. Our assumption is that socio-demographic factors as well as different study orientations could be associated with students' knowledge structures. A study orientation is here understood as a combination of interrelated features of learning. ${ }^{[33,34]}$ Based on previous research, the pivotal study orientations are meaning-orientation and reproduction-orientation. ${ }^{[35]}$ Meaning-orientation refers to the construction of knowledge and self-regulation of learning, and reproduction-orientation refers to the memorizing of detailed knowledge and external regulation of learning. ${ }^{[34]}$ Students' study orientations can also be evaluated from the perspective of their interest in studying: that is, whether they have a lack of interest or not. ${ }^{[36]}$ Thus, we explore whether there are differences in students' knowledge structures in relation to their study orientations and socio-demographic factors.

This current study focuses on a novel connection between nursing students' learning and their support of patient empowerment. By assessing nursing students' knowledge structures of an empowering discourse we aim to discover students' understanding of implementing an empowering dis- 
course. Students' knowledge structures are assessed pre- and post-test in connection to using a computer simulation program. Based on prior studies ${ }^{[8,13,14]}$ we hypothesize that a computer simulation program might be an appropriate learning method for developing knowledge structures of a multifaceted empowering discourse and students' understanding of this discourse.

\section{MeTHODS}

\subsection{Aim}

The aim of the study was to evaluate nursing students' knowledge structures of an empowering discourse, and the changes in those structures after using a computer simulation program. Furthermore, the aim was to compare these possible changes with the students' background factors.

\subsection{Research design}

This was a clustered random sample pre-test-post-test study without a control group. ${ }^{[37]}$ A mixed-methods approach to data analysis was used to obtain an enhanced and enriched understanding of the changes of the students' knowledge structures. ${ }^{[38]}$

\subsection{Setting}

This study was conducted in Finnish polytechnics representing the East, North, South and West of Finland. The total number of participating polytechnics was six.

\subsection{Sampling process}

Randomly-selected cluster sampling was used to create a sample of graduating nursing students from eight of the 20 Finnish polytechnics. From each geographical area, students were drawn from one randomly selected polytechnic with over five thousand students and one polytechnic with under five thousand students. Finally, the data were collected from only six polytechnics, because data collection was not successful in one Southern and one Northern polytechnic due to the students' time schedules.

\subsection{Sample}

A total of 242 students fulfilled the eligibility criteria, that they: 1) followed the nursing curriculum schedule, 2) were not exchange students from outside Finland, and 3) were not on maternity leave. Altogether, 101 students participated in the study representing $42 \%$ of the students $(n=101 / 242$ students). In the pre-test phase, 32 responses were excluded because the documentation of their participation in the intervention was not saved into the computer system due to a technical problem. In the post-test phase, 43 students participated, representing $62 \%$ of the participants $(n=43 / 69)$. The

Published by Sciedu Press final sample consisted of the 43 students who participated in both phases.

\subsection{The computer simulation program}

A computer simulation program was based on the theory of cognitive empowerment, ${ }^{[4,39,40]}$ previous research on an empowering discourse ${ }^{[6]}$ and the idea of constructive learning $^{[41]}$ as well as the idea of learner control. ${ }^{[7,42]}$

The program consisted of a simulated empowering discourse between a nurse and a virtual female patient admitted to hospital for a knee arthroscopy as a day case. The structure of this discourse included the phases of initiation, progression and conclusion. The empowering discourse included six content areas. ${ }^{[7]}$ In addition, the computer simulation program consisted of orientation information for using the program and learning material about an empowering discourse based on scientific nursing literature. ${ }^{[4,39,43]}$

\subsection{Educational intervention}

The principle investigator (PI) established intervention implementation at each polytechnic with a teacher of the polytechnic and sent an invitation letter including information about the study to the nursing students. The teachers' task was to recruit students to participate in the study.

For the educational intervention, the computer program was used once, through the Internet, in extra-curricular computer classes in the polytechnics during 90-minute educational sessions. The students used the computer simulation independently, and were oriented and instructed by the principal investigator and the program itself. The principal investigator attended each session to provide technical support.

In the computer simulation program, the students took the role of the nurse and were trained through the structure of an empowering discourse with the virtual patient. The students were able to choose which of the phases (initiation, progression or conclusion) they practiced.

The training methods within the simulation included a multiple-choice method and an open-ended method. Again, the students were able to choose which methods they used. In the multiple-choice method, the discourse contained 41 different questions and comments by the patient, and 123 responses and comments by the nurse. The nurse's responses to the simulated patient's questions and comments were presented one by one, in a random order, on the computer screen. The students evaluated the empowering effect of the nurse's responses on a dichotomous scale (yes-no). After this training, the students got feedback by the program on a dichotomous scale (correct-incorrect) about their choices. In the open-ended method, the discourse contained 41 different 
questions and comments by the patient. The students wrote down the nurse's response to the patient in their own words. After their responses, the students received model responses by the program, from which they could self-evaluate whether their response supported the patient's empowerment or not. For example, one comment by the virtual patient about an ethical issue was as follows: "I have read about patient's rights and malpractice." and the model response was as follows: "There is a patient ombudsman in the hospital. If you want further information, you can contact her."

\subsection{Data collection methods}

Two main tools were used for the data collection:

\subsubsection{A structured questionnaire consisting of two parts}

The first part included the students' socio-demographic factors: age, basic education, prior vocational education and healthcare education, prior patient education studies, and prior experience of patient education. These factors were measured since they were considered essential for developing of the knowledge structure of an empowering discourse. ${ }^{[8]}$

The second part focused on the students' study orientations. These study orientations were measured using two instruments: the shortened version of the Task Booklet of Learning $^{[44]}$ and one summative variable of the Inventory of General Study Orientations. ${ }^{[45]}$

The Task Booklet of Learning was used to measure students' meaning-orientation and reproduction-orientation. Their meaning-orientation was measured with nine items of two summative variables (construction of knowledge, self-regulation of learning) on a scale from 1 (= low meaning orientation) to 5 (= high meaning orientation). Their reproduction-orientation was measured with 18 items of four summative variables (intake of learning, external regulation of learning, lack of regulation, dualistic conception of knowledge) on a scale from 1 (= low reproduction orientation) to 5 (= high reproduction orientation). ${ }^{[34]}$

The summative variable of the Inventory of General Study Orientations ${ }^{[45]}$ was used to measure the students' interest in studying, with 10 items on a scale from 1 (= fully disagree) to 5 (= fully agree). ${ }^{[45]}$

\subsubsection{A concept-map method}

A concept-map method was used to measure students' knowledge structures of an empowering discourse. This datacollection method was chosen since it has been shown to be an effective method to assess students' knowledge structures in higher education research ${ }^{[14,18,20]}$ and to express students' knowledge structures directly. ${ }^{[17]}$

\subsection{Data collection procedure}

The PI organized and conducted the data collection in the polytechnics.

The pre-test data (socio-demographic factors, study orientations, concept map) were collected just prior to the students using the computer simulation. The PI introduced the data-collection method to the students and confirmed that they understood the concept-map method and how to create a concept map. All the students were familiar with the conceptmap method, based on the use of it in previous studies, in all the polytechnics. Therefore, the students were not taught in detail how to prepare concept maps at this point.

The students drew a free-form concept map independently on blank paper before using the computer simulation program. The topic provided for the map was the "identification of patients' prior knowledge and knowledge expectations in an educational discourse". The concepts "patient's prior knowledge" and "knowledge expectations" were defined briefly in connection with the topic. The students could freely select the main concept for their maps and create their maps.

The post-test data (concept map) were gathered one week after using the computer simulation. The students were instructed to prepare another concept map with the same topic at home and send their concept map by mail, in an envelope provided for the purpose, to the PI.

\subsection{Analysis}

The data were analyzed in three stages: 1) analysis of the pretest phase, 2) analysis of the post-test phase, and 3) analysis of the changes in the knowledge structures and associations between these changes and the students' background factors.

\subsubsection{Analysis of the pretest phase}

In the pre-test phase, the students' background factors were described. Background factors including socio-demographic factors and study orientations were then analyzed using descriptive statistics.

In addition, their knowledge structures were analyzed by the PI using qualitative analysis to discover their complexity by using a modified SOLO classification (see Table 1) based on Biggs and Collis's ${ }^{[12]}$ classification. The SOLO classification was conducted in regard to the structure of the empowering discourse, as described in Figure 1.

\subsubsection{Analysis of the post-test phase}

In the post-test phase, the students' knowledge structures were analyzed based on the same criteria (see Table 1) as in the pre-test phase. 
Table 1. Modified SOLO criteria for assessment of knowledge structure

\begin{tabular}{ll}
\hline SOLO class & Assessment criteria \\
\hline 1 & $\begin{array}{l}\text { Instruction and concept map do not correspond to each other, or the main concept is not identifiable, or concept map } \\
\text { has not been made } \\
\text { Concepts demonstrate one appropriate content area, and this content area is described in either a single or multiple } \\
\text { hierarchy level, and there are no cross links between the concepts } \\
\text { Concepts demonstrate two or several appropriate content areas, and these content areas are described in either a single } \\
\text { or multiple hierarchy level, and there are no cross links between the concepts } \\
\text { Concepts demonstrate two or several appropriate content areas, and these content areas are described in a multiple } \\
\text { hierarchy level, and there are cross links between the concepts } \\
\text { Concepts demonstrate two or several appropriate content areas, and these content areas are described in a multiple } \\
\text { hierarchy level, and there are cross links between the concepts, and some concepts describe abstract nursing principles }\end{array}$ \\
\end{tabular}

\subsubsection{Analysis of the changes in the students' knowledge structures and associations between these changes and the background factors}

In the third stage of the analysis, the changes in the students' knowledge structures and their associations were analyzed. These changes in the knowledge structures were analyzed statistically through a comparison of the pre- and post-test SOLO levels. For this comparison, the original qualitative SOLO levels were considered as quantitative variables on an ordinal scale as follows: prestructural $=1$, unistructural $=$ 2 , multistructural $=3$, relational $=4$ and extended abstract $=5$. The changes in the SOLO levels were tested with the Pearson's Chi-square test or Fisher's exact test. In all these tests, $p$-values less than .05 were considered as statistically significant. All statistical analyses were conducted with SAS, version 9.1.

The association between the changes in the students' knowledge structures and their study orientations was only evaluated for the students who were either clearly reproductionoriented or clearly meaning-oriented and for the students who were clearly interested or who totally lacked interest in studying. These groups were selected because it was assumed that any potential differences would arise most clearly between these groups.

To test the associations between the changes in the students' knowledge structures and their study orientations (meaningorientation and reproduction-orientation), a k-cluster analysis (three cluster model) was performed. A summative variable (lack of interest) was categorized by using tertiles, of which the first group represented students with the highest interest in studying and last group represented students with the lowest interest in studying.

The differences between changes in the knowledge structures and students' socio-demographic factors and study orientations were tested using the Chi-square test or Fisher's exact test.

Published by Sciedu Press

\subsection{Ethics}

The permission to carry out this study was received from each of the six polytechnics. The students were informed before their participation about the purpose of the study and their right to withdraw from the study at any point. The students gave their consent to participate by voluntarily creating the concept maps and responding to the questionnaire. ${ }^{[46]}$

\section{Results}

\subsection{Sample characteristics}

A total of 43 students from six polytechnics returned the concept map pre-test and post-test and were thus enrolled in the study. The students' socio-demographic factors are described in detailed in Table 2 . The mean age of the students was 25 years (range $21-48$ ).

Table 2. Students' socio-demographic background $(\mathrm{n}=43)$

\begin{tabular}{lll}
\hline Variables & $\mathbf{n}$ & $\mathbf{\%}$ \\
\hline Age, years & 30 & 70 \\
$21-24$ & 13 & 30 \\
$25 \leq$ & & \\
Basic education & 12 & 28 \\
$\quad$ Comprehensive school (9-years) & 31 & 72 \\
$\quad$ High school/college (12-years) & & \\
Prior professional education & 27 & 63 \\
$\quad$ No professonal education & 8 & 19 \\
$\quad$ Vocational education & 7 & 16 \\
$\quad$ College/polytechnic education & 1 & 2 \\
$\quad$ University & & \\
Prior patient education studies & 2 & 5 \\
$\quad$ Studies only in theory & 2 & 5 \\
$\quad$ Studies only in clinical practice & 39 & 90 \\
$\quad$ Studies both in theory and clinical practice & & \\
Prior experience of patient education & 0 & 0 \\
$\quad$ No experience & 9 & 21 \\
Experience in clinical practice & 2 & 5 \\
Experience in health care work & 32 & 74 \\
Experience in clinical practice and health care work & & \\
\hline
\end{tabular}


All the students were assessed in terms of the factors related as in terms of their interest in studying. Students' study to meaning-orientation and reproduction-orientation as well orientations are described in Table 3.

Table 3. Students' study orientations

\begin{tabular}{|c|c|c|c|}
\hline \multirow[t]{2}{*}{ Study orientations } & All students $(n=43)$ & $\begin{array}{l}\text { Meaning-oriented } \\
\text { students }(\mathrm{n}=9)\end{array}$ & $\begin{array}{l}\text { Reproduction-oriented } \\
\text { students }(\mathrm{n}=\mathbf{1 1})\end{array}$ \\
\hline & mean (SD) & mean (SD) & mean (SD) \\
\hline Meaning-oriented learning & & $4.03(0.32)$ & $2.51(0.27)$ \\
\hline Construction of learning & $3.77(0.61)$ & $4.33(0.31)$ & $3.52(0.41)$ \\
\hline Self-regulation of learning & $2.55(0.92)$ & $3.78(0.61)$ & $1.69(0.30)$ \\
\hline Reproduction-oriented learning & & $2.61(0.42)$ & $3.40(0.38)$ \\
\hline Intake of knowledge & $3.28(0.79)$ & $2.47(0.81)$ & $3.73(0.46)$ \\
\hline External regulation of learning & $3.19(0.79)$ & $2.95(0.71)$ & $3.95(0.54)$ \\
\hline Lack of regulation & $2.05(0.83)$ & $1.71(0.40)$ & $2.48(1.05)$ \\
\hline Conception of knowledge & $3.50(0.63)$ & $3.28(0.70)$ & $3.43(0.40)$ \\
\hline Lack of interest & $2.22(0.78)$ & not available & not available \\
\hline
\end{tabular}

3.2 Students' pre-test and post-test knowledge structures

The students' knowledge structures were on different complexity levels, which varied from a prestructural to an extended, abstract level at both pre- and post-test (see Table 4). Looking at them in more detail, the students' knowledge structures were prevalently multistructural both preand post-test (pre-test $44 \%$, post-test $58 \%$ ). This multistructural knowledge structure included many single concepts with no cross links. The concepts illustrated elements of the empowering discourse: initiation of the discourse, for example concentrating on knowing the patient's background, features, feelings and expectations; the content of the empowering discourse, focusing mainly on bio-physiological and functional issues; and supporting the patient's participation in the discourse.

Table 4. SOLO classification of the students' knowledge structures in pretest and post-test

\begin{tabular}{llllll}
\hline \multirow{2}{*}{ SOLO level } & \multicolumn{2}{l}{ Pretest } & & & \multicolumn{2}{c}{ Post-test } \\
\cline { 2 - 3 } \cline { 6 - 6 } \cline { 5 - 6 } & $\mathbf{n}$ & $\mathbf{0}$ & & $\mathbf{n}$ & $\mathbf{\%}$ \\
\hline Prestructural & 6 & 14 & & 5 & 12 \\
Unistructural & 8 & 19 & & 5 & 12 \\
Multistructural & 19 & 44 & & 25 & 58 \\
Relational & 8 & 19 & & 5 & 12 \\
Extended abstract & 2 & 4 & & 3 & 6 \\
\hline
\end{tabular}

Only two students $(5 \%)$ pre-test and three $(7 \%)$ post-test had a well-organized, extended, abstract-level knowledge structure. These students' knowledge structures consisted of concepts and some cross links describing all the main elements of an empowering discourse, including concepts about creating an appreciative atmosphere, negotiating the patient's health problem and the goal of the discourse, the patient's existing knowledge and knowledge needs (and the assessment of this knowledge), supporting the patient's active participation, and concluding the discourse including an assessment of the patient's understanding. The students also described some abstract principles, for example individuality and trustworthiness.

The knowledge structures of 14 students (33\%) pre-test and ten students $(23 \%)$ post-test were poorly organized, being either prestructural or unistructural. A students' prestructural knowledge structure was realized by their not drawing the concept map at all (pre-test $2 \%$, post-test $2 \%$ ), by just listing the grouped concepts under a relevant heading without any links (pre-test $2 \%$, post-test $2 \%$ ) or by providing two separate concept maps instead of being able to identify one main concept (pre-test $2 \%$, post-test $2 \%$ ). Students' unistructural knowledge structures consisted of a concept map covering only one element of the empowering discourse, for example bio-physiological issues, which the nurse and patient would discuss.

\subsection{Changes in students' knowledge structures}

Changes in the students' knowledge structures were measured by comparing the knowledge structures created preand post-test (see Table 5). About one fifth of the students (19\%) had an improved knowledge structure of the empowering discourse, reflecting more complexity, in post-test. This development occurred in the unstructured knowledge structures described with the lowest SOLO levels, with the growth of the increase being one or two levels towards a betterorganized knowledge structure. Only one student's (2\%) knowledge structure changed from a unistructural (SOLO level 2) to an extended abstract level structure (SOLO level 
5) containing concepts of all the elements of an empowering discourse. Three students (7\%) who had described only one, or some separate, elements of the empowering discourse pre-test subsequently described several elements and also linked some concepts together post-test. Four (9\%) students' knowledge structures were extended at the post-test, from containing one element or being completely disorganized pretest to including some separated elements of the empowering discourse post-test.

Table 5. Changes in the students' knowledge structures

\begin{tabular}{lll}
\hline Changes & $\mathbf{n}$ & $\mathbf{\%}$ \\
\hline Improved & 8 & 19 \\
No change & 27 & 63 \\
Regressed & 8 & 19 \\
\hline
\end{tabular}

Eight students' (19\%) knowledge structures regressed posttest. This mainly occurred in the form of a regression from a relational to multistructural knowledge structure. The regression was primarily seen from a relational level to a multistructural level in six (14\%) students' knowledge structures. At the pre-test, these six students all had well-structured knowledge structures, containing some crosslinks between some concepts, but post-test these crosslinks were missing, thus reflecting a multistructural knowledge structure. However, the changes in terms of SOLO levels were not statistically significant. The knowledge structures of $63 \%$ of the students remained unchanged.

\subsection{The association of students' study orientations and socio-demographic factors with the changes in their knowledge structures}

To answer the third research question we evaluated the association between the changes of the knowledge structure and students' socio-demographic factors as well as their study orientations. There were no statistically significant differences between the changes in the complexity of the students' knowledge structures and the students' socio-demographic factors.

There were no statistically significant differences in the changes in the level of the knowledge structures between the reproduction-oriented and meaning-oriented students or between the interested and uninterested students.

\section{Discussion}

\subsection{Discussion of the students' knowledge structures and changes}

This study aimed to evaluate how nursing students structure their knowledge of an empowering discourse related to patient education. It also evaluated the possible changes in these knowledge structures. We found that the students' knowledge structures of an empowering discourse were mainly fragmented, both pre- and post-test. This finding indicates that students' knowledge structures may not express sufficient understanding of an empowering discourse. This result is in line with previous studies ${ }^{[21,23]}$ on nursing students' knowledge structures. Therefore, there is a need for a learning method that would better support the development of students' knowledge structures about an empowering discourse.

Our main finding was that the development of students' knowledge structures of an empowering discourse can be supported by using a computer simulation as a learning method. This study showed that the development was greatest in students whose knowledge structure was initially poorly organized. Less advancement was seen in students whose knowledge structures were well organized from the beginning. Thus, computer simulations may be considered as an appropriate learning method, especially for students whose knowledge structure is not yet well organized. Computer simulation of an empowering discourse may extend students' knowledge structures, but it may only partly support students in deepening previously well-organized knowledge structures. Nevertheless, this study provided a new perspective on using computer simulation in nursing education ${ }^{\text {[26-32] }}$ and indicated the need for the development of teaching and support for students when learning about empowering patient education.

It is noteworthy that eight students had more poorly organized knowledge structures post-test. This regression occurred in the knowledge structures of the middle levels. This regression occurred in the knowledge structures of the middle levels. These knowledge structures may reflect an understanding of multiple empowering elements, although the relational level may also demonstrate the ability to link issues together. These structural levels seem to be, therefore, very similar to each other and it may be supposed that a fluctuation in knowledge structures will arise when skills are being developed. This finding may also indicate that it takes longer for some students' knowledge structures about an empowering discourse to become well organized. In addition, some students' knowledge structures might be seen to regress if the student is not interested in creating concept maps or not interested in the actual method of learning.

Moreover, this study provided a new perspective on the evaluation of the changes of the students' knowledge structures, particularly in terms of the students' study orientations. Our findings showed that changes in the students' knowledge structures did not associate with the students' socio- 
demographic factors or with the students' study orientations. This result may indicate that computer simulation is a useful learning method for nursing students regardless of their study orientations. Previous study ${ }^{[7]}$ concerning the use of computer simulation as a learning method showed that all students, even if they have different study orientations and socio-demographic factors, might be able to control the use of a simulation program.

\subsection{Limitations and strengths of the study}

There are some limitations in this study, primarily connected to the study design, sample size, duration of intervention, using concept maps as an evaluation method and the analysis of the knowledge structures. This study was conducted without a control group, which can be seen as a limitation. However, a pre-test-post-test design has also been proven to be appropriate when evaluating novel teaching methods. ${ }^{[37]}$

Since the sample size was fairly small $(n=43)$, generalizations must be made with caution. However, the sample's strength is in its representativeness. The sample was selected randomly and the polytechnics represented both large and small polytechnics from different geographical areas. The students' socio-demographic backgrounds were typical when compared to Finnish participants in other nursing education studies. ${ }^{[47,48]}$ In addition, the sample size can be considered sufficient for the qualitative evaluation of students' knowledge structures. However, the duration of intervention and one week period for information processing were also short. Although the findings were encouraging, conclusions must thus be considered with caution, and more testing is needed in the future.

The students' concept maps did not include connecting links between the concepts. This is a limitation when evaluating the meanings of the concepts used. ${ }^{[19]}$ However, the advantage of using the concept map method was that the students' knowledge structures could be directly reached through the maps ${ }^{[18]}$ and the students' individual interpretations of the empowering discourse could thus be discovered. ${ }^{[19]}$

The trustworthiness of the analysis of the knowledge structures were examined from the perspective of credibility, dependability and transferability. Credibility here refers to having confidence that the data and analysis can address the intended focus of the study. ${ }^{[49]}$ In this study, the credibility was supported by consistence between the concept map data and its analysis and the pedagogical strategies of this study.
The use of the SOLO classification strengthened the qualitative evaluation of the knowledge structures. However, this could produce weaker findings, particularly in poorly organized knowledge structures, since all of the concept maps with two main concepts were automatically classified as prestructural, reflecting the weakest knowledge structure. For credibility, the PI along with five other researchers evaluated six SOLO classifications, reaching $100 \%$ consensus after $61 \%$ initial agreement. Secondly, dependability refers to the degree to which data changes over time. ${ }^{[49]}$ In this study, the dependability was strengthened by the analysis being conducted in strict compliance with the SOLO classification in the pre-test and post-test phases. Lastly, transferability refers to the extent to which findings can be transferred to other sample or setting. ${ }^{[49]}$ In this study, the transferability is decreased by the fact that only 43 students out of 69 students drew concept maps, and that this group only represented Finnish nursing students. However, this study was carried out in typical nursing schools.

\section{Conclusions}

Our study provides new insight into using computer simulation for students learning about the empowering discourse between a nurse and a patient. We were able to show that computer simulation may support this learning by advancing a student's poorly organized knowledge structure. We also found that nursing students, even during their last year of education, do not have a clear picture of how to support patients in becoming empowered in their own care. We should therefore invest in methods that can teach the empowerment of patient education to students. If students do not have a clear picture of the empowering discourse they will not be able to facilitate high quality patient education. Poor knowledge structures do not allow nurses to build new knowledge onto existing knowledge, and thus the nurses' advancement after graduation might remain restricted.

\section{ACKNOWLEDGEMENTS}

The authors would like to thank English language and copy editor Suzanne Collins for the language revision. This study was financially supported by grants from The Finnish Foundation for Nursing Education.

\section{CONFlicts of Interest Disclosure}

The authors declare that there is no conflict of interest statement.

\section{REFERENCES}

[1] European Commission 2005, Directive 2005/36/EC. Available from: http://eur-lex.europa.eu/LexUriServ/LexUriServ
.do?uri=0J : L : 2005: 255:0022:0142: en:PDF

[2] Tuning project 2012, Tuning educational structures in Europe. Reference points for the design and delivery of degree programs in nursing. 
Available from: http://www . unideusto.org/tuningeu/image s/stories/key_documents/tuningnursingfinal.pdf

[3] Hoving C, Visser A, Dolan MP, et al. A history of patient education by health professionals in Europe and North America: From authority to shared decision making education. Patient Educ Couns. 2010; 78: 275-281. PMid:20189746 http://dx.doi.org/10.1016/j.pec .2010 .01 .015

[4] Leino-Kilpi H, Luoto E, Katajisto J. Element of empowerment and MS patients. J Neurosci Nurs. 1998; 30: 116-123. http: //dx.doi.org/10.1097/01376517-199804000-00005

[5] Tveiten S, Knutsen IR. Empowering dialogues - the patients' perspective. Scand J Caring Sci. 2011; 25(2): 333-340. PMid:21564148 http://dx.doi.org/10.1111/j.1471-6712.2010.00831.x

[6] Virtanen H, Leino-Kilpi H, Salanterä S. Empowering discourse in patient education. Patient Educ Couns. 2007; 66: 140146. PMid:17349769 http://dx.doi.org/10.1016/j.pec. 200 6.12 .010

[7] Virtanen H, Leino-Kilpi H, Leinonen K, et al. Student control over using computer simulation for learning of empowering discourse in nursing education. Comput, Inform, Nurs. 2013; 31: 512522. PMid:23958965 http://dx. doi .org/10.1097/01. NCN. 00 00432119.56581 .24

[8] Novak JD. Learning, creating, and using knowledge: Concept maps as facilitative tools in schools and corporations. 2nd Edition. 2010, New York: Routledge.

[9] Jonassen DH, Beissner K, Yacci M. Structural Knowledge: Techniques for Representing, Conveying, and Acquiring Structural Knowledge. 1993, Routledge, New York. Available from: http://books.google.fi/books?id=f2IqE8RuYpwC\&print

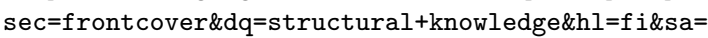
$\mathrm{X} \& \mathrm{e} i=\mathrm{cvlVVKTAD} 83$ VdGmgBA\&ved=0CBIQ6AEwAA\#v=onepage $\& q=$ structural $\% 20 \mathrm{knowledge} \& \mathrm{f}=\mathrm{false}$

[10] Koubek RJ, Mountjoy DN. Toward a model of knowledge representation and a comparative analysis of knowledge representation measurement techniques. 1991, Dayton: Wright State University.

[11] Shavelson RJ. Some aspects of the correspondence between content structure and cognitive structure in physics instruction. J Educ Psychol. 1972; 63: 225-234. http://dx.doi.org/10.1037/h0032 652

[12] Biggs J, Collis KF. Evaluating the quality of learning. The SOLO taxonomy (Structured of the observed learning outcome). 1982, Inc., New York: Academic Press.

[13] Azzarello J. Use of the Pathfinder scaling algorithm to measure students' structural knowledge of community health nursing. J Nurs Educ. 2007; 46: 313-318. PMid:17711068

[14] Kinchin IM, Hay DB. How a qualitative approach to concept map analysis can be used to aid learning by illustrating patterns of conceptual development. Educ Res. 2000; 42: 43-57. http://dx.doi . org/10.1080/001318800363908

[15] Coderre S, Jenkins D, Mclaughlin K. Qualitative differences in knowledge structure are associated with diagnostic performance in medical students. Adv Health Sci Educ. 2009; 14: 677-684. PMid:19107567 http://dx.doi.org/10.1007/s10459-008-9149-8

[16] McLaughlin K, Coderre S, Mortis G, et al. Can concept Sorting provide a reliable, valid and sensitive measure of medical knowledge structure? Adv Health Sci Educ. 2007; 12: 265-278. PMid:17072769 http://dx.doi.org/10.1007/s10459-005-6029-3

[17] Novak JD, Gowin DB. Learning to learn. 1984, New York: Cambridge University Press. http: //dx.doi .org/10.1017/CB09781 139173469

Published by Sciedu Press
[18] Shavelson RJ, Ruiz-Primo MA, Wiley EW. Windows into the mind. High Educ. 2005; 49: 413-430. http://dx.doi.org/10.1007/s 10734-004-9448-9

[19] Hay DB. Using concept maps to measure deep, surface and nonlearning outcomes. Stud High Educ. 2007; 32: 39-57. http://dx.d oi.org/10.1080/03075070601099432

[20] Ifenthaler D, Masduki I, Seel NM. The mystery of cognitive structure and how we can detect it: tracking the development of cognitive structures over time. Instr Sci. 2011; 39: 41-61. http: //dx.doi.org/10.1007/s11251-009-9097-6

[21] Azzarello J. Knowledge structures and problem representations: How do novice and expert home care nurses compare? Southern Online Journal of Nursing Research. 2003; 4. Available from: http://www.resourcenter.net/images/SNRS/Files /SOJNR_articles/iss02vol04.html

[22] Petersson G. Medical and nursing students' development of conceptions of science during three years of studies in higher education. Scand J Educ Research. 2005; 49: 281-296. http://dx.doi .org /10.1080/00313830500109592

[23] Leino-Kilpi H. Learning to care - A qualitative perspective of student evaluation. J Nurs Educ. 1989; 28: 61-66. PMid:2466970

[24] Little M. Preparing nursing students to be health educators: Personal knowing through performance and feedback workshops. J Nurs Educ. 2006; 45: 131-135. PMid:16562803

[25] Choi HWH, Hui G, Lee A, et al. Student nurses' experiences and challenges in providing health education in Hong Kong. Nurse Educ Today. 2010; 30: 355-359. PMid:19819050 http://dx.doi.org $/ 10.1016 / j$.nedt . 2009.09.005

[26] Weis PA, Guyton-Simmons J. A computer simulation for teaching critical thinking skills. Nurse Educ. 1998; 23: 30-33. http: //dx.doi.org/10.1097/00006223-199803000-00014

[27] Jeffries P, Woolf S, Linde BA. Comparison of two methods for teaching the skill of performing a 12-lead ECG. Nurs Educ Perspect. 2003; 24: 70-74. PMid:12743975

[28] Botsis T, Halkiotis ST, Kourlaba G. Computer simulation of the human respiratory system for educational purposes. Comput Inform Nurs. 2004; 22: 162-170. http://dx.doi.org/10.1097/00024 665-200405000-00011

[29] Jeffries P. Development and test of a model for designing interactive CD-ROMs for teaching nursing skills. Comput Inform Nurs. 2000; 18: $118-124$.

[30] Jeffries P. Development and testing of a hyperlearning model for design of an online critical care course. J Nurs Educ. 2005; 44: 366-372. PMid:16130343

[31] Kiegaldie D, White G. The virtual patient - development, implementation and evaluation of an innovative computer simulation for postgraduate nursing students. JEMH. 2006; 15: 31-47.

[32] Durmaz A, Dicle A, Cakan E, et al. Effect of screen-based computer simulation on knowledge and skill in nursing students' learning of preoperative and postoperative care management. A randomized controlled study. Comput Inform Nurs. 2012; 30: 196203. PMid:22228217 http://dx.doi .org/10.1097/NCN.0b013 e3182419134

[33] Entwistle NJ, Ramsden P. Understanding student learning. 1983, London: Croom Helm.

[34] Nieminen J, Lindblom-Ylänne S, Lonka K. The development of study orientations and study success in students of pharmacy. Instr Sci. 2004; 32: 387-417. http://dx.doi.org/10.1023/B : TRUC. 0000044642.35553. e5

[35] Richardson J. Meaning orientation and reproducing orientation: 1997 A typology of approaches to studying in higher education? Educ 
Psychology. 1997; 17: 301-311. http://dx.doi.org/10.1080/0 144341970170305

[36] Lonka K, Olkinuora E, Mäkinen J. Aspects and prospects of measuring studying and learning in higher education. Educ Psychol Rev. 2004; 16: 301-323. http://dx.doi.org/10.1007/s10648-004 $-0002-1$

[37] Cook T, Campbell D. Quasi-Experimentation. Design \& Analysis Issues for Field Settings.1979, Boston: Houghton Miffilin Company.

[38] Johnson RB, Onwuegbuzie AJ. Mixed Methods Research: A Research Paradigm Whose Time Has Come. Educ Res. 2004; 33: 14-26. http://dx.doi.org/10.3102/0013189X033007014

[39] Heikkinen K, Leino-Kilpi H, Hiltunen A, et al. Ambulatory orthopaedic surgery patients' knowledge expectations and perceptions of received knowledge. J Adv Nurs. 2007; 60: 270-278. PMid:17908124 http://dx.doi.org/10.1111/j.1365-2648. 2007.04408.x

[40] Ryhänen A, Rankinen S, Siekkinen M, et al. The impact of an empowering Internet-based Breast Cancer Patient Pathway programme on breast cancer patients' knowledge: A randomised control trial. Patient educ Couns. 2012; 88: 224-231. PMid:22425373 http://dx.doi.org/10.1016/j.pec.2012.02.013

[41] Biggs J. Teaching for quality learning at university. What the student does. 2003, 2nd edition, Townbridge: The Cromwell Press.

[42] Vandewaetere M, Clarebout G. Can instruction as such affect learning? The case of learner control. Comput Educ. 2011; 57: 2322-2332. http://dx.doi.org/10.1016/j.compedu. 2011.05.020

[43] Rankinen S, Salanterä S, Heikkinen K, et al. Expectations and received knowledge by surgical patients. Int J Qual Health Care. 2007;
19: 113-119. PMid:17277008 http://dx.doi.org/10.1093/i ntqhc/mzl075

[44] Lindblom-Ylänne S, Lonka K. Individual ways of interacting with the learning environment - are they related to study success? Learn Instruct. 1999; 9: 1-18. http://dx.doi .org/10.1016/S0959-4 752 (98) 00025-5

[45] Mäkinen J. University students' general study orientations. Theoretical background, measuments, and practical implications. Annales Universitatis Turkuensis, Ser. B, Tom. 262, Humaniora. 2003. Turku: University of Turku.

[46] TENK. Responsible conduct of research and procedures for handling allegations of misconduct in Finland. Finnish Advisory Board on Research Integrity. 2012. Available from: http://www.tenk.fi/ sites/tenk.fi/files/HTK_ohje_2012.pdf

[47] Lakanmaa R, Suominen T, Perttilä J, et al. Competence requirements in itensine and ctitical care nursing - Still in need of definition? A Delphi study. Intensive Crit Care Nurs. 2012; 28: 329336. PMid:22534494 http://dx.doi.org/10.1016/j.iccn. 20 12.03 .002

[48] Suikkala A, Leino-Kilpi H, Katajisto J. Factors related to the nursing student-patient relationship: The students' perpective. Nurse Educ Today. 2008; 28: 539-549. PMid:17935835 http://dx.doi.org $/ 10.1016 / j$.nedt . 2007.09.004

[49] Graneheim UH, Lundman U. Qualitative content analysis in nursing research: Concepts, procedures and measures to achieve trustworthiness. Nurse Educ Today. 2004; 24: 105-112. PMid:14769454 http://dx.doi.org/10.1016/j.nedt.2003.10.001 